\title{
Evaluation of a family-oriented antenatal group educational program in rural Tanzania: a pre-test/post-test study
}

\author{
Yoko Shimpuku1* D, Frida E. Madeni², Shigeko Horiuchi ${ }^{1}$, Kazumi Kubota ${ }^{3}$ and Sebalda C. Leshabari ${ }^{4}$
}

\begin{abstract}
Background: To increase births attended by skilled birth attendants in Tanzania, studies have identified the need for involvement of the whole family in pregnancy and childbirth education. This study aimed to develop, implement, and evaluate a family-oriented antenatal group educational program to promote healthy pregnancy and family involvement in rural Tanzania.
\end{abstract}

Methods: This was a quasi-experimental 1 group pre-test/post-test study with antenatal education provided to pregnant women and their families in rural Tanzania. Before and after the educational program, the pre-test/post-test study was conducted using a 34-item Birth Preparedness Questionnaire. Acceptability of the educational program was qualitatively assessed.

Results: One-hundred and thirty-eight participants (42 pregnant women, 96 family members) attended the educational program, answered the questionnaire, and participated in the feasibility inquiry. The mean knowledge scores significantly increased between the pre-test and the post-test, 7.92 and 8.33 , respectively $(p=0.001)$. For both pregnant women and family members, the educational program improved Family Support ( $p=0.001$ and $p=0.000$ ) and Preparation of Money and Food ( $p=0.000$ and $p=0.000$ ). For family members, the scores for Birth Preparedness $(p=0.006)$ and Avoidance of Medical Intervention (reversed item) $(p=0.002)$ significantly increased. Despite the educational program, the score for Home-based Value (reversed item) $(p=0.022)$ and References of SBA $(p=0.049)$ decreased in pregnant women. Through group discussions, favorable comments about the program and materials were received. The comments of the husbands reflected their better understanding and appreciation of their role in supporting their wives during the antenatal period.

Conclusions: The family-oriented antenatal group educational program has potential to increase knowledge, birth preparedness, and awareness of the need for family support among pregnant women and their families in rural Tanzania. As the contents of the program can be taught easily by reading the picture drama, lay personnel, such as community health workers or traditional birth attendants, can use it in villages. Further development of the Birth Preparedness Questionnaire is necessary to strengthen the involved factors. A larger scale study with a more robust Birth Preparedness Questionnaire and documentation of skilled care use is needed for the next step.

Trial registration: No.2013-273-NA-2013-101. Registered 12 August 2013.

Keywords: Pregnancy, Childbirth, Family support, Birth preparedness, Antenatal education, Africa

\footnotetext{
* Correspondence: shimpuku.yoko.5n@kyoto-u.ac.jp

${ }^{1}$ Human Health Sciences, Graduate School of Medicine, Kyoto University, 53

Shogoin-kawahara-cho, Sakyo-ku, Kyoto 606-8507, Japan

Full list of author information is available at the end of the article
}

(c) The Author(s). 2018 Open Access This article is distributed under the terms of the Creative Commons Attribution 4.0 International License (http://creativecommons.org/licenses/by/4.0/), which permits unrestricted use, distribution, and reproduction in any medium, provided you give appropriate credit to the original author(s) and the source, provide a link to the Creative Commons license, and indicate if changes were made. The Creative Commons Public Domain Dedication waiver (http://creativecommons.org/publicdomain/zero/1.0/) applies to the data made available in this article, unless otherwise stated. 


\section{Plain English summary}

One of the biggest challenges facing Tanzania is the large number of women who die from pregnancy and childbirth, reflecting the need for better antenatal education. In response to this need, our group of Japanese and Tanzanian midwives developed an antenatal group educational program for teaching the importance of birth preparedness and family involvement in pregnancy in rural Tanzania. For the educational material, we developed a picture drama which compared the stories of two women who had different birth preparations and family involvement. We provided the program to pregnant women and their families in Kiswahili, and asked them to fill questionnaires before and after the program and to join the discussion regarding their thoughts about the program. There were 138 participants who attended the program, answered the questionnaires, and participated in the discussion. Their knowledge of danger signs of pregnancy increased. Moreover, their perceptions toward family support and preparation of money and food improved. Family members showed better preparedness for birth and less avoidance of medical intervention. The comments about the program and materials were favorable. The husbands' comments reflected better understanding and appreciation of their role in supporting their wives during the antenatal period. Taken together, the antenatal group educational program increased knowledge, birth preparedness, and awareness of the need for family involvement and support among pregnant women and their families in rural Tanzania. Educational programs using picture dramas could add an acceptable component for increasing birth preparedness among pregnant women and their families especially in rural areas.

\section{Background}

In 2015, the Sustainable Development Goals of the United Nations were published on the basis of the achievement of the Millennium Development Goals (MDGs) [1-3]. According to the MDGs Report, greater effort is needed to reduce the global burden of maternal mortality [1]. Although a $45 \%$ reduction of maternal mortality in developing countries is a significant achievement, still about 289,000 women died in 2013 from causes related to pregnancy and childbirth [1]. World Health Organization (WHO), ICM (International Confederations of Midwives), and FIGO (International Federation of Gynecology and Obstetrics) have suggested that to reduce maternal mortality, skilled birth attendants (SBAs), namely, midwives, nurses, or doctors, should assist all births [4]. In rural areas of Tanzania, however, only 54\% of all deliveries were reportedly conducted by SBAs [5]. Thus, nearly half of rural women still either chose not to use SBAs or had no access to SBAs while giving birth.
Researchers have indicated that Birth Preparedness and Complication Readiness (BP/CR) could be a key factor in influencing the choice of birthplace with SBAs [6-8]. In the WHO publication of Birth and Emergency Preparedness in Antenatal Care [9], 9 birth preparation components were identified: (1) the desired place of birth; (2) the preferred birth attendant; (3) the location of the closest appropriate care facility; (4) money for birth-related and emergency expenses; (5) a birth companion; (6) support in looking after the home and children while the woman is away; (7) transport to a health facility for the birth; (8) transport in the case of an obstetric emergency; and (9) identification of compatible blood donors in case of emergency. Despite the importance of $\mathrm{BP} / \mathrm{CR}$ to promote SBAs, several reports have suggested a low level of BP/CR among women in African settings [10-13].

To increase BP/CR, 2 review studies have shown the accumulated findings of interventions. One study reviewed 58 articles and identified that community-based information, education, and communication interventions, which taught women when to reach out for assistance, increased awareness and knowledge of the danger signs of pregnancy complications [14]. This increase of women's awareness and knowledge has resulted in an increase in the utilization of health facility delivery services [14]. Another study using systematic review and meta-analysis found that exposure to $\mathrm{BP} / \mathrm{CR}$ interventions was associated with a significant reduction of $18 \%$ in neonatal mortality risk (12 studies, $\mathrm{RR}=0.82$; $95 \% \mathrm{CI}$ : $0.74,0.91$ ) and a nonsignificant reduction of $28 \%$ in maternal mortality risk (7 studies, RR $=0.76$; 95\% CI: 0.69, 0.85) [15]. Both home visits and community-based women's group sessions have been reported to potentially reduce the risk of neonatal mortality; however, their effects on maternal health have not been fully clarified. Moreover, home-based individual counseling has been found to be more personalized and appropriate for developing mothers' personal knowledge and skills [15]. However, other studies have revealed the lack of decision-making power of women within their family with regard to the referral and place of birth [16-18].

Intra-family or extended family decision-making also influences women's choices for childbirth [19]. The values and opinions of the husband, mother-in-law, mother, traditional birth attendant, other family members, and community members have been shown to have more influence in decisions regarding the birth place than the pregnant woman's input [19]. Implementation of the $9 \mathrm{BP} / \mathrm{CR}$ components requires family support. This implies that the decision-maker of the household, mostly the husband, must agree to provide the financial support for transportation and funds for emergency support, and the family or extended family should provide 
for child care, arrange for possible transport, be prepared to donate blood if necessary, and come to an agreement regarding the location for childbirth [20]. Even though husbands were typically the decision-makers regarding the place of delivery, they were rarely encouraged to attend antenatal sessions [21, 22]. August et al. [20] specifically interviewed husbands regarding their understanding of $\mathrm{BP} / \mathrm{CR}$ and found them lacking particularly in the area of identifying an SBA. Therefore, community-based activities were still needed to promote family involvement because in these traditional settings the locus of decision-making was more community-based than individual-based [15]. WHO [16] recommended using BP/CR education and discussion with community participation, particularly the involvement of the male partner and other householder decision-makers.

It was found in Uganda that women who prepared for birth in consultation with their family members were more likely to give birth with the help of SBAs than women who prepared for birth by themselves [7]. A previous study investigating the partners' influence on women delivering at a health facility in Tanzania found that the agreements of partners on the importance of delivering in a health facility and on doctors having better skills than traditional birth attendants were associated with delivery in a health facility [21].

For over a decade, studies conducted in Tanzania have identified the need for involvement of the whole family in pregnancy and childbirth education [23-26]. Shimpuku et al. [26] emphasized the importance of family involvement in pregnancy and childbirth because it improved the quality of care and women's birth experiences.

Therefore, the role of the family in decision-making is a crucial issue for reducing maternal mortality, with the place of birth being an important component. However, there are only few studies that have examined family-based education. We therefore performed the present study to evaluate our recently developed family-oriented antenatal group educational program for pregnant women and their family members in rural Tanzania.

\section{Methods}

\section{Study design}

This was a quasi-experimental, 1 group pre-test/post-test study that included a qualitative component addressing feasibility. The family-oriented antenatal group educational program was provided to increase birth preparedness.

\section{Setting}

We conducted this study in Korogwe district, which is located in the center of the Tanga Region of North Eastern Tanzania. Korogwe has a total area of 3756 sq. km with 132 villages [27]. The main economic activities include agriculture and horticulture involving the natural resources of forests and game parks. The Korogwe district is predominately rural with a large population of 175,339 in reference to an urban area of 43,510. The Korogwe district has 1 public hospital and 2 private hospitals, 3 health centers, and 59 dispensaries. According to Demographic Health Survey 2 (DHS2) in 2016, delivery at health facilities 6969, deliveries with Traditional Birth Attendant (TBA) 259, home deliveries without TBA 151, birth before arrival 118 [28].

\section{Sampling method and sample size}

With the support of a local collaborator, we purposefully selected 3 mountain villages where the nearest health center was located at least $5 \mathrm{~km}$ away, and the majority of women deliver at home. As the villages were located in the mountain, women in these villages must walk unpaved mountain roads to reach the nearest health center. The roads become completely dark after sunset; therefore, preparation of transportation and financial support was necessary to reach skilled care because contractions could start unpredictably, even at night.

We aimed to recruit a total sample size of 100 participants (50 pregnant women and 50 family members) to meet the assumption of a normal distribution [29]. Hence, 100 participants were expected to attend the program and pre-test/post-test. The inclusion criteria for women were as follows: currently pregnant with no severe physical or psychological illness. We did not exclude women based on gestational weeks or number of pregnancies. The criteria for family members were as follows: 16 years old or older, living with or near the pregnant woman, and defined as "family" by the pregnant woman (regardless of their blood or marital relationship). Participants need to be able to read Kiswahili to complete the self-administered questionnaire. If they need assistance in answering the questionnaire, a research assistant helped for reading and marking the answer.

\section{Recruitment and data collection process}

We requested the village leaders to inform their constituents about our research activities and to ask pregnant women and their families to gather in a school or a church on a specified date and time. When we arrived in the village, pregnant women and their families gathered at the specified place. After explaining the details of our research, they were asked if they agreed to participate in the study. Because of the interest of those who gathered in the study, all agreed to participate and stayed to receive the educational program and pre-test/ post-test. This data collection process was repeated in 2 more villages. 


\section{Educational program}

We developed the family-oriented antenatal group educational program to be culturally relevant. The program lasted for approximately 2 hours and included a pre-test/post-test, picture drama, and discussion. In the educational program, pregnant women and their families were taught the importance of birth preparation to increase the safety of childbirth, namely, survival of pregnant women and their babies. The program aimed to inculcate the following ideas: (1) preparation for childbirth is important to enable women to receive health care when necessary, (2) families are encouraged to support the women's choice when deciding their birth place, and (3) women are advised to give birth with an SBA. We created a story of women's birth experiences based on a qualitative study at a rural hospital in Tanzania [26]. The story included health promotion concepts such as family decision-making processes, and family support according to the Integrated Management of Pregnancy and Childbirth [9].

At the beginning of our family-oriented antenatal group educational program, the participants were asked to answer the Birth Preparedness Questionnaire (BPQ) pre-test. The second author (FM), a female Tanzanian researcher, who has a master's degree with knowledge of local customs, shared a story using a picture drama. The picture drama depicted 2 women who had very different birth experiences, one with and one without proper birth preparation. The first woman had a very supportive family. She attended antenatal visits regularly. At the visits, a midwife provided information about nutrition, danger signs during pregnancy, risks of some traditional herbs, potential problems of the mother and baby, and necessary preparations including money, transportation, birth companions, and blood donors in case of emergency. As a result, this first woman who had properly prepared for birth with her family had a normal delivery of a healthy baby. The second woman had a family who strongly believed in home birth and did not allow her to go to antenatal visits. Because the family did not prepare anything, when the woman's labor become obstructed, they delayed leaving for the hospital and consequently, the family lost both the mother and the baby. The pictures clearly depicted the story and illustrated Tanzanian housing and clothes (kanga) to enable the participants to easily identify with the story.

In community settings, utilization of picture drama was found to be educationally effective. An increase in knowledge was found when providing reproductive health education using picture dramas to adolescent boys and girls in Tanzania [30]. The pictures made it easier for those who were not strong in health literacy to understand the contents. All important information was written on the backside of the pictures. This enabled the presenter to be consistent and provide comprehensive information. After the picture drama and the presenter's explanation, the participants were asked to answer the same BPQ for the post-test and then to evaluate the contents and effectiveness of the antenatal group educational program.

\section{Measurements}

Demographic items included age, marital status, education, occupation, daily monetary use, household assets, ethnic group, distance from health care facility, experience in losing a family member owing to pregnancy problems, and obstetric history (only pregnant women).

\section{Birth preparedness questionnaire}

The BPQ is a 34-item self-administered questionnaire consisting of a knowledge test and a $\mathrm{BP} / \mathrm{CR}$ assessment that was used for both the pre-test ad the post-test. In the development of the questionnaire, the authors utilized Ajzen's theory [31] as a guide. The theory explains that intentions to perform various behaviors can be predicted from the following 3 perceptional components: 1) perceived behavioral control, 2) attitudes toward the behavior, and 3) subjective norms. The authors chose this theory to frame items related to those 3 psychological factors that may influence intention to have an SBA.

Knowledge items were added to the questionnaire because previous studies have indicated that adequate knowledge of danger signs was associated with more SBA-attended births [32, 33]. We developed a self-administered 10-item knowledge test about safe pregnancy and danger signs based on the 9 components of Integrated Management of Pregnancy and Childbirth [9]. The items are presented as binary yes/no responses. Another 24-item BP/CR assessment test was developed to assess $\mathrm{BP} / \mathrm{CR}$ and the items were related to psychological values and beliefs. These 24 items were rated using a 3-point Likert scale indicating (1) disagree, (2) neither disagree nor agree, or (3) agree.

The questionnaire was first developed in English and then translated into Kiswahili, which is a more familiar language to most Tanzanians. The questionnaire was translated by the second author (FM) who is bilingual in Kiswahili and English, from the same district, and experienced in communicating with rural Tanzanian women. Initially, to increase face validity, 10 rural women were interviewed regarding their answers for the knowledge test and BP/CR assessment. They were asked to provide their opinions regarding any unclear or confusing questions. Thereafter, the knowledge test and BP/CR assessment were revised according to the opinions of the interviewed women and finalized for this study.

As it was the first time to introduce the program to Tanzania, a feasibility inquiry was conducted in the form 
of a group discussion that included all the women and their family members attending the program, followed by completion of a post-test questionnaire. This feasibility inquiry was conducted to initially determine if the delivery of the program was acceptable to the participants. The participants responded to open-ended questions to assess the feasibility of the study. The following questions were included: 1) "How did you feel about the contents of the picture drama? Did you understand it well? If not, what was difficult to understand?" 2) "Are the contents of the picture drama appropriate for educating rural women and their family members?" 3) "How can we improve the contents of the picture drama?". While observing the discussions, field notes were taken and data were transcribed in Kiswahili and then translated into English. Thematic content analysis [34] was used based on the predetermined concepts of acceptability, demand, implementation, practicality, and limited efficacy [35]. The field notes were carefully read and similar ideas were extracted, then the major ideas were discussed. Thus, the major findings were organized into 5 categories.

\section{Ethics approval and consent to participate}

The study was conducted based on the principles of ethics such as harmlessness, being voluntarily, anonymity, and protection of privacy and personal information. We explained these principles during recruitment along with the purpose, methods, and ethical considerations. We asked each participant if they agreed to participate in the study and only those who agreed were included in the study. We obtained verbal consent because the information gathered was unidentifiable and the risk from this study was minimal. Ethical clearance and permissions were obtained from the 1) Research Ethics Committee of St. Luke's International University (14-040); 2) Director of the Korogwe District Council, 3) National Institute for Medical Research, Tanzania (NIMR/HQ/R.8/ Vol.IX/1604), and 4) Tanzania Commission for Science and Technology (No. 2013-273-NA-2013-101).

\section{Data analysis}

SPSS ver. 22.0 was used for descriptive analysis, correlations, exploratory factor analysis using the maximum likelihood method and promax rotation to validate the factor structure. Exploratory factor analysis was conducted using the 28 original $\mathrm{BP} / \mathrm{CR}$ items to determine whether measures of the construct were consistent with authors' understanding of the nature of that construct. Before the analysis, the answers for all the reverse items were inversed (from 1 to 3 and from 3 to 1). Four items were excluded during the analysis because of low correlations. The final factor analysis included the remaining 24 items. As a result, 7 factors were identified:
Home-based Value (Factor I, 7 items, Cronbach's alpha = 0.846), Birth Preparedness (Factor II, 5 items, Cronbach's alpha $=0.691$ ), Family Support (Factor III, 4 items, Cronbach's alpha =0.646), Avoidance of Medical Intervention (Factor IV, 2 items, Cronbach's alpha $=0.548$ ), Preparation of Money and Food (Factor V, 2 items, Cronbach's alpha $=0.615$ ), Preference of SBA (Factor VI, 2 items, Cronbach's alpha $=0.472)$, Pregnant Women's Workload (Factor VII, 2 items, Cronbach's alpha= 0.337). Table 1 shows the results of factor analysis. Wilcoxon signed-rank test was used to determine any significant difference in the BP/CR scores before and after the educational program. For the feasibility inquiry, the qualitative data were analyzed using thematic content analysis.

\section{Results}

\section{Demographic and obstetric characteristics}

There were a total of 139 prospective participants from 3 villages (42 pregnant women and 97 family members). One participant did not complete the questionnaire and was therefore excluded. Hence, 138 participants (42 pregnant women and 96 family members) were included for the analysis. Table 2 shows a summary of the participants' characteristics. Although the group included both pregnant women and their family members, there was no significant difference in education, occupation, daily expenses, or household assets. There was a significant difference in the mean age $(p<0.001)$. Among the 42 pregnant women, $8(19 \%)$ were primipara and 34 were multipara $(M=1.45, S D 1.194$, range $0-5)$. For antenatal visits, 17 (40.5\%) attended once and 23 (54.8\%) attended twice ( 2 had missing data). There were 24 multiparas who had given birth at a health facility, one of whom had caesarean section. None had lost a baby during pregnancy or childbirth. All the participants attended the antenatal group educational program and the feasibility inquiry.

\section{Pre-test and post-test differences in knowledge}

Figure 1 shows that the mean knowledge score of all the participants significantly increased between pre-test and post-test $(p=0.001)$. After the education, both pregnant women and family members showed significantly higher means in knowledge scores $(p=0.011$ and $p=0.020$, respectively).

\section{Pre-test/post-test differences in BPQ}

There were significant differences between pre-test and post-test both in pregnant women and family members in Family Support ( $p=0.001$ and $p=0.000$, respectively) and Preparation of Money and Food ( $p=0.000$ and $p=$ 0.000 , respectively). Table 3 shows the mean score and standard deviation of the 7 factors between pregnant 


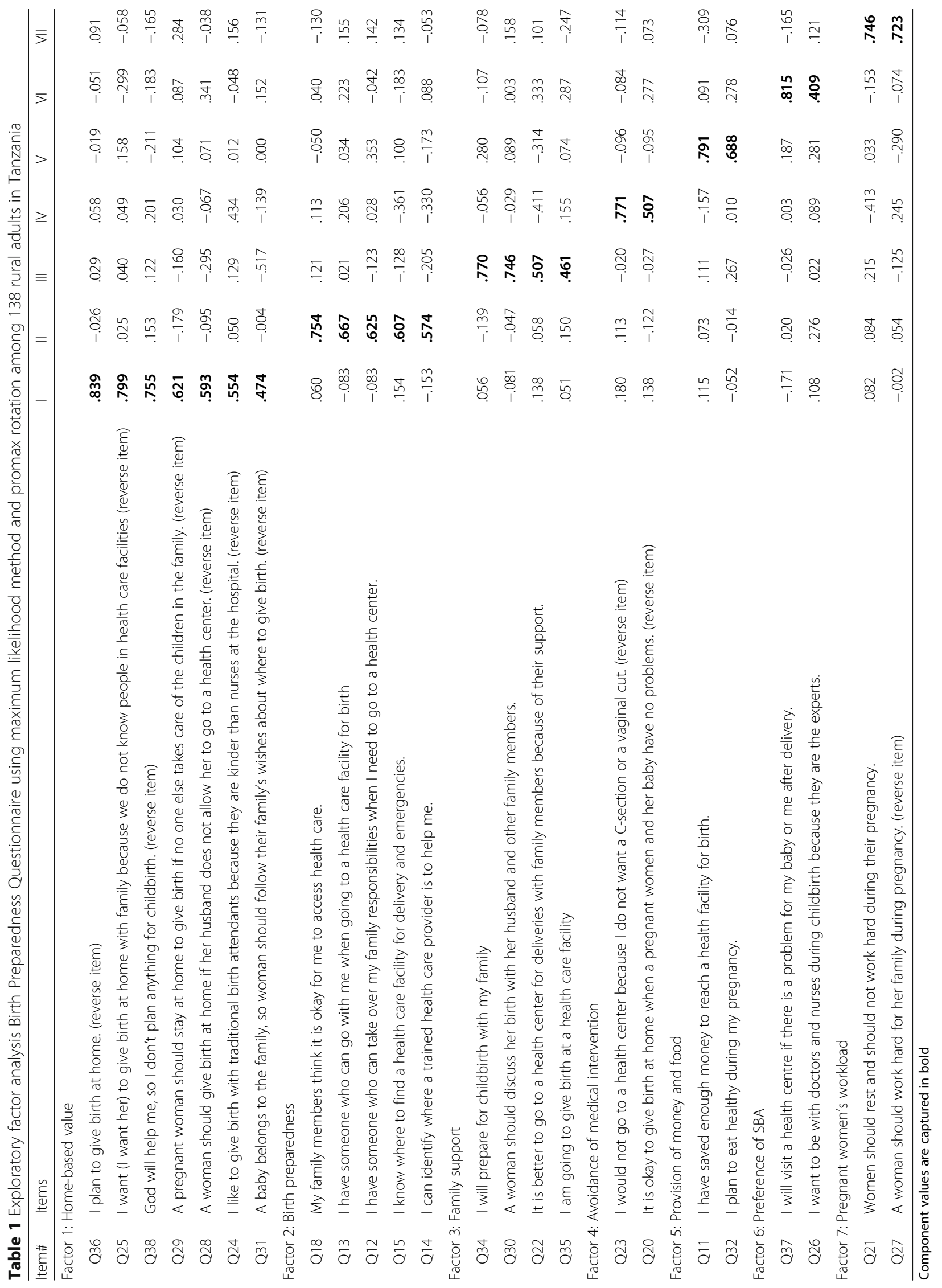


Table 2 Comparison of the sociodemographic characteristics of the participants

\begin{tabular}{|c|c|c|c|c|c|}
\hline & \multicolumn{2}{|c|}{ Pregnant women $(N=42)$} & \multicolumn{2}{|c|}{ Family $(N=96)$} & \multirow[t]{2}{*}{$p$-value } \\
\hline & Mean (SD) & n (\%) & Mean (SD) & n (\%) & \\
\hline Age & 27.67 & & 35.29 & & $<0.001$ \\
\hline Educational level & & & & & 0.148 \\
\hline Lower than secondary level & & $34(82.9)$ & & $62(73.8)$ & \\
\hline Secondary level and above & & $7(17.1)$ & & $22(26.2)$ & \\
\hline Missing data & & $1(2.4)$ & & $12(12.5)$ & \\
\hline Occupation & & & & & 0.203 \\
\hline Farmer & & $33(80.5)$ & & $63(73.3)$ & \\
\hline Housewife/student & & $8(19.5)$ & & $23(26.7)$ & \\
\hline Missing data & & $1(2.4)$ & & $10(10.4)$ & \\
\hline Daily expense & & & & & 0.662 \\
\hline$<1000$ TSH & & $18(42.9)$ & & $39(47.0)$ & \\
\hline $1000-5000$ TSH & & $21(50.0)$ & & $32(38.6)$ & \\
\hline$\geq 5000 \mathrm{TSH}$ & & $3(7.1)$ & & $12(14.4)$ & \\
\hline Missing data & & 0 & & $13(13.5)$ & \\
\hline Household assets ownership & & & & & 0.83 \\
\hline $\operatorname{Low}(0-1)$ & & $38(90.5)$ & & $70(75.3)$ & \\
\hline High (2+) & & $4(9.5)$ & & $23(24.7)$ & \\
\hline Missing data & & 0 & & $3(3.1)$ & \\
\hline
\end{tabular}

women and family members for the pre-test and post-test. There was a significant decrease in two reversed items of Home-based Value and Preference of SBA ( $p=0.022$ and $p=0.049$, respectively) among only pregnant women. There were significant differences in Birth Preparedness and Avoidance of Medical Intervention ( $p=0.006$ and $p=0.002$, respectively) among only family members.

\section{Correlation among BPQ factors}

Among the 7 factors, Home-based Value was positively associated with Avoidance of Medical Intervention ( $r=$ $0.55, p=0.000)$ and Pregnant Women's Workload ( $r=$ $0.22, p=0.011)$ and negatively associated with Family Support $(r=-0.34, p=0.000)$ and Preparation of Money and Food $(r=-0.26, p=0.000)$. Birth Preparedness was positively associated with Family Support $(r=0.26, p=$

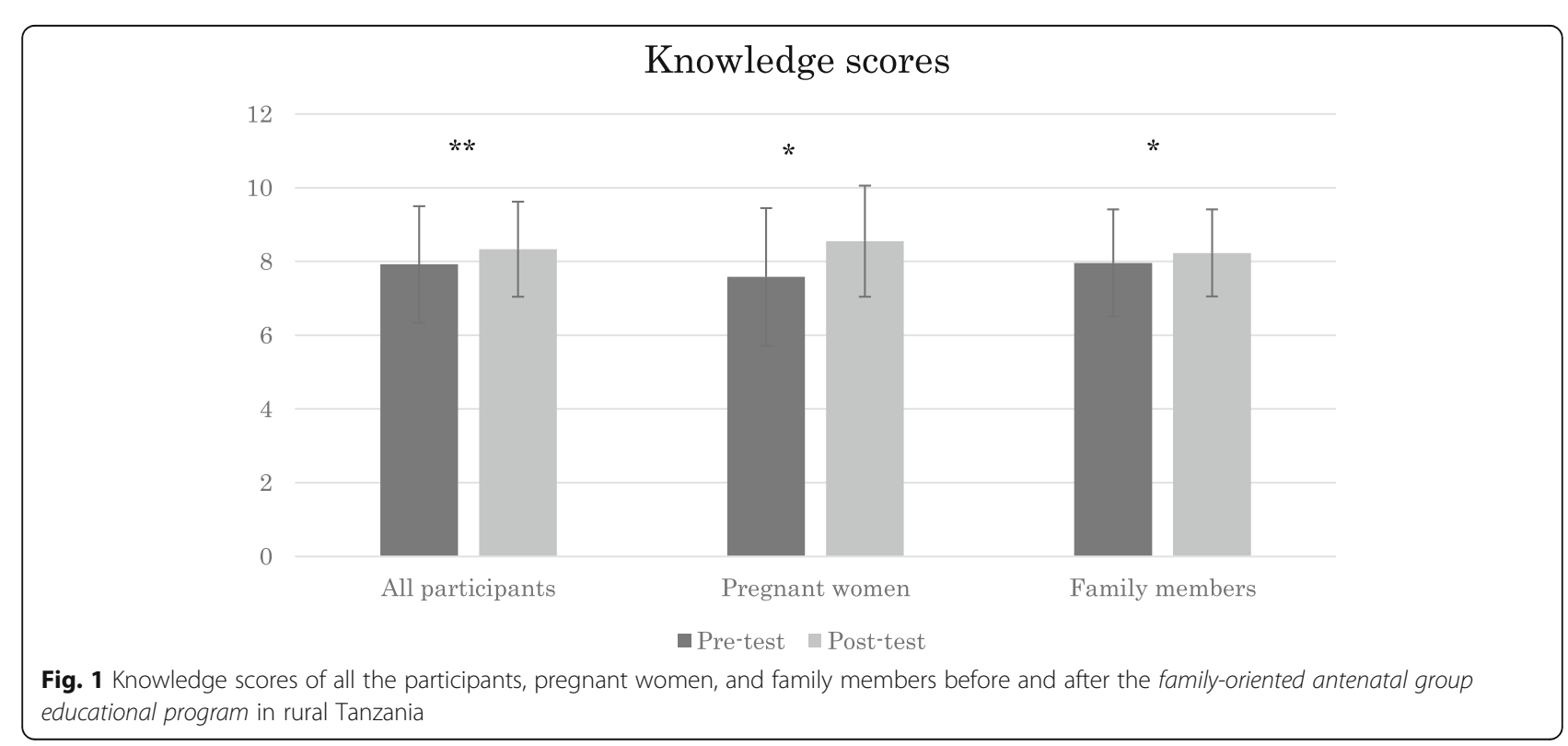


Table 3 Comparison of pre-test/post-test Birth Preparedness Questionnaire scores among pregnant women and family members

\begin{tabular}{|c|c|c|c|c|c|c|}
\hline & \multicolumn{3}{|c|}{ Pregnant women $(n=42)$} & \multicolumn{3}{|c|}{ Family members $(n=96)$} \\
\hline & Pre & Post & $p$ & Pre & Post & $p$ \\
\hline 1) Home-based Value & $17.32(3.49)$ & $16.33(3.88)$ & $0.022^{*}$ & $16.33(3.88)$ & $16.24(3.51)$ & 0.312 \\
\hline 2) Birth Preparedness & $14.13(1.07)$ & $14.38(1.01)$ & 0.135 & $14.38(1.01)$ & $13.99(1.76)$ & $0.006^{* *}$ \\
\hline 3) Family Support & $10.02(1.76)$ & $11.18(1.58)$ & $0.001^{* *}$ & $11.18(1.58)$ & $10.95(1.52)$ & $0.000^{* *}$ \\
\hline 4) Avoidance of Medical Intervention & $3.92(1.61)$ & $4.25(1.56)$ & 0.078 & $4.25(1.56)$ & $4.26(1.37)$ & $0.002^{* *}$ \\
\hline 5) Preparation of Money and Food & $4.77(1.28)$ & $5.68(0.75)$ & $0.000^{* *}$ & $5.68(0.75)$ & $5.71(0.66)$ & $0.000^{* *}$ \\
\hline 6) Preference of SBA & $5.78(0.70)$ & $5.51(0.93)$ & $0.049^{*}$ & $5.51(0.93)$ & $5.53(0.77)$ & 0.105 \\
\hline 7) Pregnant Women's Workload & $4.80(1.31)$ & $5.08(1.11)$ & 0.108 & $5.08(1.11)$ & $4.64(1.10)$ & 0.215 \\
\hline
\end{tabular}

${ }^{*} p<0.05,{ }^{* *} p<0.01$

Note: The Wilcoxon signed-rank test. The $p$-value is asymptotic significance (two-tailed)

0.002), Preparation of Money and Food $(r=-0.28, p=$ $0.001)$, and Preference of SBA $(r=0.24, p=0.05)$, and negatively associated with Avoidance of Medical Intervention $(r=-0.29, p=0.001)$. Family Support was positively associated with Preparation of Money and Food $(r$ $=0.41, p=0.000)$ and Preference of SBA $(\mathrm{r}=0.26, p=$ 0.003 ) and negatively associated with Avoidance of Medical Intervention $(r=-0.27, p=0.002)$. Avoidance of Medical Intervention was negatively associated with Preparation of Money and Food $(r=-0.25, p=0.003)$. Preparation of Money and Food was positively associated with Preference of SBA $(r=0.31, p=0.000)$.

\section{Feasibility inquiry}

Bowen et al. [35] suggested 8 general areas of focus for a feasibility study: acceptability, demand, implementation, practicality, adaptation, integration, expansion, and limited efficacy. Within these areas, this study focused on acceptability, demand, implementation, practicality, and limited efficacy, which fit with the preliminary stage of this study. The details and outcomes are described in Table 4.
Acceptability indicates how the intended participants and program staff react to the intervention [35]. Regarding the educational materials in this study, a woman shared, "The picture is good and makes it easy for us to understand." Another woman mentioned, "We are very happy to learn many things, no one feels bad. Everybody is happy." After the education, a woman said, "Husbands should change their behaviors. For example, giving the women heavy loads." One man stated, "We learned how to make a good relationship between pregnant women and their families." Another man expressed, "We learned to increase love to unborn baby and his/her mother."

Demand indicates the estimated or actual use of the intervention. As an example of demand, a man stated, "We need to tell the government to add more health centers to the villages near people's houses." Another man mentioned, "This type of education should be given to all Tanzanian people, pregnant women, and their families."

Implementation indicates the extent, likelihood, and manner in which an intervention is fully implemented. In this study, more time was needed to complete the self-administered questionnaire than as planned.

Table 4 Observations and qualitative data for the feasibility inquiry

\begin{tabular}{|c|c|c|}
\hline Focus areas & Questions in feasibility inquiry ${ }^{a}$ & Study outcomes \\
\hline Acceptability & $\begin{array}{l}\text { To what extent is a new idea, program, process or measure } \\
\text { judged as suitable, satisfying, or attractive to program deliverers? } \\
\text { To program recipients? }\end{array}$ & $\begin{array}{l}\text { "The picture is good and enables us to easily understand." "We } \\
\text { are very happy to learn many things, no one feels bad. } \\
\text { Everybody is happy." }\end{array}$ \\
\hline Demand & $\begin{array}{l}\text { To what extent is a new idea, program, process, or measure } \\
\text { likely to be used (i.e., how much demand is likely to exist?) }\end{array}$ & $\begin{array}{l}\text { "This type of education should be given to all Tanzanian people, } \\
\text { pregnant women and their families." }\end{array}$ \\
\hline Implementation & $\begin{array}{l}\text { To what extent can a new idea, program, process, or measure } \\
\text { be successfully delivered to intended participants in some } \\
\text { defined, but not fully controlled, context? }\end{array}$ & $\begin{array}{l}\text { It takes more time to complete the self-administered question- } \\
\text { naire than what was planned by the researchers. }\end{array}$ \\
\hline Practicality & $\begin{array}{l}\text { To what extent can an idea, program, process, or measure be } \\
\text { carried out with intended participants using existing means, } \\
\text { resources, and circumstances and without outside intervention? }\end{array}$ & $\begin{array}{l}\text { The collaborator can conduct the intervention, but more local } \\
\text { nurses or community health workers need to be educated to } \\
\text { implement the intervention and expand the research. }\end{array}$ \\
\hline Limited efficacy & $\begin{array}{l}\text { Does the new idea, program, process, or measure show promise } \\
\text { of being successful with the intended population, even in a } \\
\text { highly controlled setting? }\end{array}$ & $\begin{array}{l}\text { The scores of the measure showed some significant differences } \\
\text { before and after the intervention with the limited convenient } \\
\text { sample. More changes are expected. }\end{array}$ \\
\hline
\end{tabular}


Practicality indicates the extent to which an intervention can be delivered depending on the available resources, time, commitment, or a combination of factors. We identified that a local collaborator can conduct the research; however, training is required to be able to extend the research.

Limited efficacy indicates whether the study was successful even at a limited extent such as the evaluation of a convenient sample. We conducted this study using a convenient sample and we found several statistically significant findings. If we conduct this study using a larger sample with possible randomization, it is expected that more significant differences will be found after the intervention.

\section{Discussion}

The family-oriented antenatal group educational program in rural Tanzania succeeded in providing information about the importance of birth preparation and how to strengthen family involvement. The program specifically improved the scores of Knowledge, Family Support, and Preparation of Money and Food among all the participants. As Knowledge increased among all the participants, the educational program utilizing a picture drama and discussion was effective and culturally compatible with the participants.

It was an important finding that Family Support changed significantly. This variable includes the items about discussion on birthplace among family members. The increase of discussion among family members including women may improve women's decision-making power within the family. Household equity indeed has also been shown to increase women's facility delivery in Nepal [36]. Notably, when Nepalese women were actually communicating with their husbands, they were more likely to discuss health issues during pregnancy and birth preparedness with their husbands, and the husbands had a higher likelihood of being present during health facility delivery [37]. When women in Guatemala [38] and Uganda [39] made a birth plan with their husbands or other family members, they were more likely to seek the care of SBAs. Thus, although we did not increase SBA-assisted deliveries this time, the educational program contributed to increasing the participation of women in decision-making and birth preparation, which could increase facility delivery with a larger sample size.

Similarly, the increase of monetary preparation from the program shows that the program had the potential to increase SBA-assisted deliveries. Other studies also showed that monetary preparation was found to be one of the key factors for achieving deliveries with SBAs $[8,33,40]$.

The next step is the necessity to improve education on Preference of SBA. Among pregnant women, the score was significantly decreased; this change was not our intent. This factor included perceptions toward health care providers. We deduced that the participants from this rural area might have had perceptions toward health care providers that the educational program did not address. For example, disrespect and abuse of birthing women by health care providers have been reported in Tanzania [41-43]. As suggested by WHO [3], education for health care providers might also be needed. Another possible area for study is a follow-up of community volunteers for women to utilize skilled care at delivery as recommended by a community-based safe motherhood program in Tanzania [44]. As the present study provided only 1 session of education, continuous education or follow-up might be a more effective method for increasing readiness to use a health facility for an emergency.

Regarding the changes in the scores between family members and pregnant women, family members showed an increase in the scores for more variables than pregnant women. For example, the scores for Birth Preparedness and Avoidance of Medical Intervention increased significantly among only the family members. Some possible explanations why the scores of pregnant women did not significantly increase were the higher pre-test scores and the smaller sample size of the pregnant women. On the other hand, the scores for the Home-based Value of women decreased significantly, which was not our intended change. As the factor was composed of reverse items, the participants might not have answered carefully and instead answered in a response set, which is the opposite course. Reverse items could be reduced so that participants answer the questionnaires as researchers intended.

The study was significant in terms of obtaining preliminary data from pregnant women and their families who were difficult to reach in rural Tanzania. The study can be further improved in terms of more efficient implementation and greater community involvement in a subsequent larger scale study. At this stage of the educational program development, the study limitations of a small sample size, less rigorous sampling methods, and no-comparison group restrict the demonstration of the robust effects of the educational program, and therefore the generalizability is limited. Due to the small sample size, normality was not confirmed, and therefore only non-parametric analysis was used. With a larger sample size, the BPQ could benefit from additional psychometric testing to clarify and strengthen the concepts. In addition, this study would benefit more if it were conducted in districts with higher home birth rate. Although this study focused on increasing the knowledge and psychological aspects of BP/CR immediately after education, it did not evaluate outcome behaviors, such as delivery at a health facility. Further study is needed to investigate 
whether the participants who received education delivered with SBAs at a health facility, and to clarify the neonatal and maternal outcomes. Ultimately, a longitudinal randomized controlled study that replicates the educational intervention and includes outcome data in rural settings of Tanzania will provide more generalizable data.

\section{Conclusions}

The family-oriented antenatal group educational program has potential to increase knowledge, birth preparedness, and awareness of the need for family support among pregnant women and their families in rural Tanzania. As the contents of the program can be taught easily by reading the picture drama, lay personnel, such as community health workers or traditional birth attendants, can use it in villages. Further development of the Birth Preparedness Questionnaire is necessary to strengthen the involved factors. A larger scale study with a more robust BPQ and documentation of skilled care use is needed for the next step.

\section{Abbreviations}

BP/CR: Birth Preparedness and Complication Readiness; BPQ: Birth Preparedness Questionnaire; MDGs: Millennium Development Goals; SBAs: Skilled Birth Attendants; WHO: World Health Organization

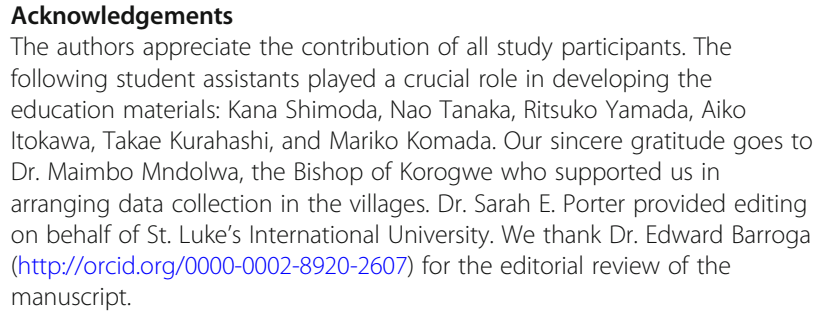

Acknowledgements

The authors appreciate the contribution of all study participants. The following student assistants played a crucial role in developing the education materials: Kana Shimoda, Nao Tanaka, Ritsuko Yamada, Aiko Itokawa, Takae Kurahashi, and Mariko Komada. Our sincere gratitude goes to Dr. Maimbo Mndolwa, the Bishop of Korogwe who supported us in arranging data collection in the villages. Dr. Sarah E. Porter provided editing on behalf of St. Luke's International University. We thank Dr. Edward Barroga (http://orcid.org/0000-0002-8920-2607) for the editorial review of the manuscript.

\section{Funding}

The study was funded by the Japan Society for the Promotion of Science, Grants-in-Aid for Scientific Research: Research Activity Start-up (No. 248902460001).

\section{Availability of data and materials}

The datasets used and analyzed during the current study are available from the corresponding author upon reasonable request.

\section{Authors' contributions}

YS conceptualized and designed of the study. YS, FM, and SL contributed to the acquisition of data. YS and KK participated in data analysis and/or interpretation. YS drafted the first manuscript. SH reviewed and suggested revisions. All authors reviewed and approved the final manuscript.

\section{Authors' information}

YS is a Japanese midwifery researcher who obtained her PhD from the University of Illinois at Chicago, USA. She has been conducting research on maternal child health and midwifery in Tanzania since 2008. She speaks fluent English and Swahili which were necessary for conducting this study. FM and SL are Tanzanian midwifery researchers who provided cultural understanding of the data. KK is a nurse and statistician who provided analytical expertise into the study. SH is a Japanese midwifery professor who has conducted, supervised, and published numerous midwifery research studies across the world, and who currently spearheads many on-going studies in this field.

\section{Ethics approval and consent to participate}

Verbal consent was obtained as the information gathered was unidentifiable and the study risk was minimal. Ethical clearance and permissions were obtained from the 1) Research Ethics Committee of St. Luke's International University (14-040); 2) Director of the Korogwe District Council, 3) National Institute for Medical Research, Tanzania (NIMR/HQ/R.8/Nol.IX/1604), and 4) Tanzania Commission for Science and Technology (No. 2013-273-NA-2013-101).

\section{Consent for publication}

Not applicable.

\section{Competing interests}

The authors declare that they have no competing interests.

\section{Publisher's Note}

Springer Nature remains neutral with regard to jurisdictional claims in published maps and institutional affiliations.

\section{Author details}

${ }^{1}$ Human Health Sciences, Graduate School of Medicine, Kyoto University, 53 Shogoin-kawahara-cho, Sakyo-ku, Kyoto 606-8507, Japan. ${ }^{2}$ Magunga District Hospital, P. O. Box 430, Old-Korogwe, Tanga, Tanzania. ${ }^{3}$ Department of Biostatistics, Yokohama City University School of Medicine, 3-9 Fukuura, Kanazawa-ku, Yokohama 236-0004, Japan. ${ }^{4}$ School of Nursing, Muhimbili University of Health and Allied Sciences, P. O. Box 65169, Dar es Salaam, Tanzania.

Received: 14 August 2017 Accepted: 18 June 2018

Published online: 28 June 2018

References

1. United Nations. The millennium development goals report. New York: United Nations; 2015.

2. United Nations Development Group. 2014. Delivering the post-2015 development agenda: opportunities at the national and local levels. Available from: [cited 2016 April 30] Available at: http://www. worldwewant2015.org/file/459043/download/499855. Accessed 20 July 2017

3. World Health Organization. 2015. WHO recommendations on health promotion interventions for maternal and newborn health. Available at: [cited 2017 January 14] http://apps.who.int/iris/bitstream/10665/172427/1/ 9789241508742_report_eng.pdf. Accessed 20 July 2017.

4. World Health Organization. 2004. Making pregnancy safer: the critical role of the skilled attendant. Available at: [cited 2016 April 30] http://www.who.int/ maternal_child_adolescent/documents/9241591692/en/. Accessed 20 July 2017.

5. Ministry of Health, Community Development, Gender, Elderly and Children (MoHCDGEC) [Tanzania Mainland], Ministry of Health (MoH) [Zanzibar], National Bureau of Statistics (NBS), Office of the Chief Government Statistician (OCGS), and ICF. Tanzania Demographic and Health Survey and Malaria Indicator Survey (TDHS-MIS) 2015-16. Dar es Salaam, Tanzania, and Rockville, Maryland, USA: MoHCDGEC, MoH, NBS, OCGS, and ICF; 2016.

6. Hailu M, Gebremariam A, Alemseged F, Deribe K. Birth preparedness and complication readiness among pregnant women in southern Ethiopia. PLoS One. 2011;6:e21432

7. Kabakyenga JK, Östergren PO, Turyakira E, Pettersson KO. Influence of birth preparedness, decision-making on location of birth and assistance by skilled birth attendants among women in south-western Uganda. PLoS One. 2012; 7:e35747.

8. Moran AC, Sangli G, Dineen R, Rawlins B, Yameogo M, Baya B. Birthpreparedness for maternal health: findings from Koupela district, Burkina Faso. J Health Popul Nutr. 2006;24:489-97.

9. World Health Organization 2006. Birth and emergency preparedness in antenatal care. Available at: http://www.who.int/reproductivehealth/ publications/maternal_perinatal_health/emergency_preparedness_ antenatal_care.pdf. Accessed 20 July 2017.

10. Kaso M, Addisse M. Birth preparedness and complication readiness in Robe Woreda, Arsi zone, Oromia region, Central Ethiopia: a cross-sectional study. Reprod Health. 2014;11:55.

11. Markos D, Bogale D. Birth preparedness and complication readiness among women of child bearing age group in Goba Woreda, Oromia region, 
Ethiopia. BMC Pregnancy Childbirth. 2014;14:282. https://doi.org/10.1186/ 1471-2393-14-282.

12. Mbalinda SN, Nakimuli A, Kakaire O, Osinde MO, Kakande N, Kaye DK. Does knowledge of danger signs of pregnancy predict birth preparedness? A critique of the evidence from women admitted with pregnancy complications. BMC Health Res Policy Syst. 2014;12:60. Available at: http://www.health-policy-systems.com/content/12/1/60. Accessed 20 July 2017.

13. Tura G, Afework MF, Yalew AW. The effect of birth preparedness and complication readiness on skilled care use: a prospective follow-up study in Southwest Ethiopia. Reprod Health. 2014;11:60. https://doi.org/10.1186/ 1742-4755-11-60.

14. Nyamtema AS, Urassa DP, van Roosmalen J. Maternal health interventions in resource limited countries: a systematic review of packages, impacts and factors for change. BMC Pregnancy Childbirth. 2011;11:30. https://doi.org/10. 1186/1471-2393-11-30

15. Soubeiga D, Gauvin L, Hatem MA, Johri M. Birth preparedness and complication readiness (BPCR) interventions to reduce maternal and neonatal mortality in developing countries: systematic review and metaanalysis. BMC Pregnancy Childbirth. 2014;14:129. https://doi.org/10.1186/ 1471-2393-14-129.

16. Mrisho M, Schellenberg JA, Mushi AK, Obrist B, Mshinda H, Tanner M, Schellenberg D. Factors affecting home delivery in rural Tanzania. Trop Med Int Health. 2007;12:862-72.

17. Pembe AB, Urassa DP, Darj E, Carlsted A, Olsson P. Qualitative study on maternal referrals in rural Tanzania: decision making and acceptance of referral advice. Afr J Reprod Health. 2008;12:120-31.

18. Pembe AB, Carlstedt A, Urassa DP, Lindmark G, Nyström L, Darj E. Effectiveness of maternal referral system in a rural setting: a case study from Rufiji district, Tanzania. BMC Health Serv Res. 2010;10:326.

19. Ganle, JK, Obeng B, Segbefia AY, Mwinyuri V, Yeboah JY, Baatiema L. How intra-familial decision-making affects women's access to, and use of maternal healthcare services in Ghana: a qualitative study. BMC Pregnancy Childbirth 2015;15:173. Available at: http://doi.org/10.1186/s12884-015-05904. Accessed 20 July 2017.

20. August F, Pembe A, Mpembeni R, Aximo P, Darj E. Men's knowledge of obstetric danger signs, birth preparedness and complication readiness in rural Tanzania. PLoS One 2015. Available at: http://dx.doi.org/10.1371/ journal.pone.0125978. Accessed 20 July 2017.

21. Danforth EJ, Kruk ME, Rockers PC, Mbaruku G, Galea S. Household decisionmaking about delivery in health facilities: evidence from Tanzania. J Health Popul Nutr. 2009;27:696-703.

22. Magoma M, Requejo J, Campbell OM, Cousens S, Filippi V. High ANC coverage and low skilled attendance in a rural Tanzanian district: a case for implementing a birth plan intervention. BMC Pregnancy Childbirth. 2010; 10(13) https://doi.org/10.1186/1471-239.

23. Kruk ME, Paczkowski M, Mbaruku G, de Pinho H, Galea S. Women's preferences for place of delivery in rural Tanzania: a population-based discrete choice experiment. Am J Public Health. 2008:99(9):1666-72.

24. Lugina HI, Lindmark G, Johansson E, Christensson K. Tanzanian midwives' views on becoming a good resource and support person for postpartum women. Midwifery. 2001;17(4):267-78.

25. Mbekenga CK, Lugina HI, Christensson K, Olsson P. Postpartum experiences of first-time fathers in a Tanzanian suburb: a qualitative interview study. Midwifery. 2011;27(2):174-80.

26. Shimpuku Y, Patil CL, Norr KF, Hill PD. Women's perceptions of childbirth experience at a hospital in rural Tanzania. Health Care Women Int. 2013;34:461-81.

27. The Planning Commission Dar es Salaam \& Regional Commissioner's Office Tanga Tanga Region Socio-Economic Profile 1997. Available at: http://www. tzonline.org/pdf/Tanga.pdf. Accessed 20 July 2017.

28. Korogwe District. Demographic health survey 2. 2016.

29. Ueda T. Statistics: approval and estimation. Tokyo Japan: Ohmsha.

30. Madeni F, Horiuchi S, lida M. Evaluation of a reproductive health awareness program for adolescence in urban Tanzania-a quasi-experimental pre-test post-test research. Reprod Health. 2011;8:21.

31. Ajzen I. Theory of planned behavior. Organ Behav Hum Decis Process. 1991; 50:179-211.

32. Pembe AB, Urassa DP, Carlstedt A, Lindmark G, Nystrom L, Darj E. Rural Tanzanian women's awareness of danger signs of obstetric complications. BMC Pregnancy Childbirth. 2009;9:12.
33. Urassa PD, Pembe BA, Mganga F. Birth preparedness and complication readiness among women in Mpwapwa district, Tanzania. Tanzanian J Health Res. 2012;14:1-7.

34. Sandelowski M. Focus on research methods: whatever happened to qualitative description? Res Nurs Health. 2000;23:334-40.

35. Bowen DJ, Kreuter M, Spring B, Cofta-Woerpel L, Linnan L, Weiner D, Bakken S, Kaplan CC, Squiers L, Fabrizio C, Fernandez M. How we design feasibility studies. Am J Prev Med. 2009;36(5):452-7. https://doi. org/10.1016/j.amepre.2009.02.002.

36. Nonyane BA, KC A, Callaghan-Koru JA, Guenther T, Sitrin D, Syed U, et al. Equity improvements in maternal and newborn care indicators: results from the Bardiya district of Nepal. Health Policy Plan. 2016;31(4):405-14. https:// doi.org/10.1093/heapol/czv077.

37. Thapa DK, Niehof A. Women's autonomy and husbands' involvement in maternal health care in Nepal. Soc Sci Med. 2013;93:1-10.

38. Becker S, Fonseca-Becker F, Schenck-Yglesias C. Husbands' and wives' reports of women's decision-making power in western Guatemala and their effects on preventive health behaviors. Soc Sci Med. 2006;62(9):2313-26.

39. Njuki R, Kimani J, Obare F, Warren C. Using verbal and social autopsies to explore health-seeking behavior among HIV-positive women in Kenya: a retrospective study. BMC Womens Health. 2014;14:77. https://doi.org/10. 1186/1472-6874-14-77.

40. Kalisa R, Malande CO. Birth preparedness, complication readiness and male partner involvement for obstetric emergencies in rural Rwanda. Pan Afr Med J. 2016;17(25):91. https://doi.org/10.11604/pamj.2016.25.91.9710.

41. Kujawski S, Mbaruku G, Freedman LP, Ramsey K, Moyo W, Kruk ME. Association between disrespect and abuse during childbirth and women's confidence in health facilities in Tanzania. Matern Child Health J. 2015; 19(10):2243-50. https://doi.org/10.1007/s10995-015-1743-9.

42. Larson E, Hermosilla S, Kimweri A, Mbaruku GM, Kruk ME. Determinants of perceived quality of obstetric care in rural Tanzania: a cross-sectional study. BMC Health Serv Res. 2014;14:483. https://doi.org/10.1186/1472-6963-14-483.

43. Sando D, Kendall T, Lyatuu G, Ratcliffe H, McDonald K, Mwanyika-Sando M, et al. Disrespect and abuse during childbirth in Tanzania: are women living with HIV more vulnerable? J Acquir Immune Defic Syndr. 2014;67(Suppl 4): S228-34. https://doi.org/10.1097/QAl.0000000000000378.

44. Mushi D, Mpembeni R, Jahn A. Effectiveness of community based safe motherhood promoters in improving the utilization of obstetric care. The case of Mtwara rural district in Tanzania. BMC Pregnancy Childbirth. 2010; 10(14) https://doi.org/10.1186/1471-2393-10-1.

\section{Ready to submit your research? Choose BMC and benefit from:}

- fast, convenient online submission

- thorough peer review by experienced researchers in your field

- rapid publication on acceptance

- support for research data, including large and complex data types

- gold Open Access which fosters wider collaboration and increased citations

- maximum visibility for your research: over $100 \mathrm{M}$ website views per year

At BMC, research is always in progress.

Learn more biomedcentral.com/submissions 